\title{
Intelectuais negros entre o século XIX e início do XX: novas perspectivas para a história da educação brasileira
}

\section{Black intellectuals between 19th and the early 20th: new alternatives for History of Brazilian Education}

Surya Aaronovich Pombo de Barros

Doutora

Universidade Federal da Paraíba João Pessoa, Paraíba-Brasil surya.pombo@gmail.com

\begin{abstract}
Quem de nós aqui ainda se permite acreditar que os esforços para retomarmos o futuro podem ser particulares ou individuais? Quem aqui ainda se permite acreditar que a busca pela libertação pode ser incumbência única e exclusiva de uma só raça, on de um só sexo, uma idade, uma religião ou classe?
\end{abstract}

Audre Lorde

Resumo: Trata-se de uma discussão sobre a presença de homens negros no cenário intelectual brasileiro no período de transição entre o século XIX e o XX. Reflete-se sobre novas perspectivas de compreensão da história da educação brasileira a partir da inclusão de pessoas negras no universo letrado. Discutem-se trajetórias de homens negros na Parahyba do Norte a partir da consulta às fontes primárias e tendo como referência teórica a história social e a história social da educação. Conclui-se sobre a importância de alargar a compreensão sobre as relações raciais entre brancos e negros no Brasil e a inclusão dessa discussão no campo da história da educação.

Palavras-chave:História da educação. População negra. Intelectuais negros. Pós-abolição.

Abstract: This article aims to discuss the presence of black men in the Brazilian intellectual scene in the time frame from the mid-19th century to the beginning of the 20th century. It reflects on new perspectives for understanding the History of Brazilian education from the inclusion of black people in the literate universe. The trajectories of black men in Parahyba do Norte will be discussed based on primary sources and taken as theoretical reference the social history and the social history of education. We conclude on the importance of broadening the understanding of race relations between whites and blacks in Brazil and the inclusion of this discussion in the field of the history of education.

Key-words: History of education. Black population. Black intellectuals. Post-abolition.

Cite como

(ABNT NBR 6023:2018)

BARROS, Surya Aaronovich Pombo de. Intelectuais negros entre o século XIX e início do XX: novas perspectivas para a história da educação brasileira. Dialogia, São Paulo, n. 37, p. 1-14, e19826, jan./abr. 2021. Disponível em: https://doi.org/10.5585/dialogia.n37.19826.

American Psychological Association (APA)

Barros, S. A. P. (2021, jan./abr.). Intelectuais negros entre o século XIX e início do XX: novas perspectivas para a história da educação brasileira. Dialogia, São Paulo, 37, p. 1-14, e19826. https://doi.org/10.5585/dialogia.n37.19826. 


\section{Introdução}

O período de transição entre o século XIX e o XX demarca uma série de mudanças fundamentais para a sociedade brasileira: fim da escravidão oficial, mudança de regime político, reedição dos debates sobre o povo brasileiro e a construção da nação. Nesse contexto, o papel da educação escolar, da participação pelo voto e da conformação racial do povo brasileiro eram elementos que estavam no centro dos debates. Pretendemos, tendo este cenário como pano de fundo, discutir a relação entre população negra e universo letrado. Destacaremos a existência de sujeitos negros que se notabilizaram em função de sua aproximação com as letras. Abordaremos a questão a partir de um campo que se encontra na intersecção entre história e educação: a história da educação brasileira.

Diferentes temas, regiões e períodos fazem parte dos esforços de pesquisa empreendidos por historiadoras e historiadores da educação. No entanto, a tradição historiográfica do campo, por muito tempo, concentrou as análises sobre a escola e as questões referentes ao universo letrado especialmente a partir das décadas de 1920 e 1930, deixando de fora os processos ocorridos ao longo do Oitocentos, e acima de tudo, apagando sujeitos históricos como mulheres, pobres, indígenas e pessoas negras.

Através de processos já discutidos em outros textos - desenvolvimento do campo, influência das pesquisas em história social, aumento de pesquisadores e pesquisadoras negras na academia, ampliação dos debates sobre relações raciais - a incorporação da população negra entre os sujeitos históricos investigados pela história da educação ocorreu desde o final dos anos 1990, se afirmando como crucial para o entendimento dos processos históricos relacionados ao desenvolvimento da educação no Brasil (BARROS, FONSECA, 2016). Se até aquele momento pessoas negras não apareciam nas pesquisas empreendidas na área, atualmente o quadro é diferente. Os trabalhos versam do período colonial ao século XXI, abarcando todas as regiões brasileiras e articulando temas como infância, gênero, docência, formação profissional, ensino noturno, etc., com a questão racial. Os sujeitos estudados variam: livres, ingênuos/as, escravos/as, libertos/as, africanos/as livres, pretos/as, pardos/as, quilombolas. Entre esses temas, uma questão que vem emergindo nas pesquisas mencionadas é a existência de pessoas de origem negra que atuaram entre a segunda metade do século XIX e início do século XX. Tais sujeitos se destacaram por sua participação nos círculos letrados desde o final do período imperial, alcançando projeção em áreas como literatura, jornalismo, direito e política, participando de debates públicos sobre temas como desenvolvimento do país e abolicionismo ainda no período de vigência da escravidão. Consideramos que sua existência informa sobre diferentes possibilidades de ser negro/a no 
período. Para discutir o tema, centraremos a análise na Parahyba do Norte, uma província da região Norte, de economia baseada na agricultura e pecuária, com presença marcante da escravidão e um grande contingente de população negra livre e liberta.

Para organizar a exposição, inicialmente discutiremos a relação entre negros/as e o universo letrado na província paraibana, demonstrando que, a despeito das adversidades, pessoas negras não estiveram alijadas do universo educacional. Em seguida, debateremos sobre a existência de letrados negros no período imperial, dialogando com a bibliografia sobre a temática. E, finalmente, apresentaremos um grupo de homens negros paraibanos, destacando a trajetória de dois sujeitos que se destacaram em espaços letrados.

\section{Parahyba do Norte, instrução e população negra}

A importância da instrução na construção da sociedade permeava discursos e ações na Parahyba do Norte, assim como em outras regiões do Brasil Império e nos primeiros anos de regime republicano. Através de fontes diversas como documentos oficiais, leis e regulamentos, discussões na imprensa e literatura memorialística, é possível perceber o desenvolvimento da escola primária paraibana desde o século XIX. Esse processo é perceptível pela ampliação da rede escolar, em debates públicos, na organização de normas sobre a instrução pública, nas discussões sobre a importância dos professores. A província contava, ainda, com uma instituição de ensino secundário, o Liceu Paraibano, frequentado pelos filhos das elites da região. Além dessas ofertas oficiais e públicas, a Parahyba do Norte as habilidades de ler e escrever eram ensinadas em escolas privadas para meninos e para meninas; em locais destinados a filhos/as de pobres e desvalidos/as, como o Colégio de Educandos Artífices e a Companhia de Aprendizes Marinheiros; aulas noturnas; aulas nas cadeias; entre outras instituições e locais. Em outras palavras, a presença da escrita e da leitura como elementos determinantes na vida social se assentava na região.

É necessário destacar que tal mudança era acompanhada por massiva presença negra: em 1872, a população paraibana era composta por 376.226 pessoas. Desses, 221.938 eram negros 188.241 pardos e 33.697 pretos, sendo que 21.526 eram cativos (ROCHA, 2009, p. 112). A diferença na condição jurídica é um elemento importante, pois a educação escolar era proibida a escravos/as (e, por vezes, a negros/as livres), em praticamente todas as legislações provinciais brasileiras, e isso se repetia na Parahyba do Norte (BARROS, 2016). Apesar da interdição jurídica e os costumes, que também dificultavam a matrícula e frequência de pessoas negras (mesmo livres), essa parte da população não ficou inteiramente alijada da escola ou do aprendizado de ler, escrever e contar. Tais sujeitos não permaneceram indiferentes à transição de uma sociedade baseada na 
oralidade para a assentada na escrita, demandando professores, solicitando abertura de aulas, tentando matricular os filhos em instituições com vagas limitadas, entre outras ações que as pesquisas sobre a região vêm explorando.

Por isso, outras possibilidades, para além da interdição, podem ser encontradas quando se mira o Oitocentos. As aulas noturnas, criadas a partir de 1870, em geral não eram proibidas a escravos, sendo destinadas a pessoas pobres e negras. Anúncios de fuga ou de venda de escravos nos periódicos paraibanos traziam, entre as características, as habilidades de ler e escrever, como no anúncio de "um menino de idade de 15 annos, de nome José Lourenço da Rocha, de côr preta, cabelos carapinhos, sêcco de corpo, saber ler e escrever [...]” (O Publicador, 7 jul 1865). As instituições destinadas à infância desvalida também são exemplos disso. O regulamento do Colégio de Educandos Artífices paraibano, de 1865, trazia entre os campos a serem preenchidos no ato da matrícula: "cor e mais sinais característicos". Os documentos da instituição mostram a presença de filhos de mulheres escravizadas entre os alunos, assim como a Companhia de Aprendizes Marinheiros, criada na província em 1871, que tinha entre os internos meninos pretos e pardos, de origem livre ou escrava.

Mesmo em escolas públicas oficiais encontramos alunos negros, como num texto de Graciliano Fontino Lordão, publicado na imprensa, em que o professor se defendia da acusação de ter maltratado alunos, "em cujo numero achava-se o filho da escrava, do qual o Sr. anunciante mostra-se campadecido pelo rigoroso castigo que lhe foi applicado, em punição d'aquella mesma falta que elle em sua censura chama espectaculo vergonhoso e digno da publica indignação!" (O Publicador, 22 jul 1868, grifos originais).

Esses exemplos, mesmo que desvios da norma, são indícios de letramento e/ou escolarização de pessoas negras, inclusive escravizadas. O exemplo da denúncia de maus tratos em relação ao "filho da escrava" é ainda mais instigante quando sabemos que o professor Graciliano Fontino Lordão era, ele mesmo, um homem pardo. Como Lordão, que além de professor atuou na política, sendo eleito deputado provincial por quatro mandatos, obteve o título de coronel e foi funcionário do Tesouro estadual, outros sujeitos “de cor" se destacaram na sociedade brasileira.

\section{Letrados negros no período imperial}

Entre final dos anos 1990 e primeira década do século XXI, a historiografia da educação começou a agregar pessoas negras entre sujeitos de práticas educacionais, de legislações e como agentes de processos envolvendo a instrução (FONSECA, 2007). A compreensão relativamente tardia da importância dessa parcela da população brasileira e sua relação com a educação foi fruto 
de diversas questões que podem ser assim resumidas: aprofundamento da discussão sobre relações raciais e educação; superação da ideia de que a escola brasileira teria incorporado camadas populares apenas a partir de sua universalização, ocorrida na segunda metade do século XX (nessa acepção, pobres teriam sido alijados da escola e entre eles, os negros); paulatino ingresso de pesquisadores/as negros/as academia; avanço na interpretação sobre legislação imperial, abandonando a ideia de que negros teriam sido proibidos de se matricular e frequentar escolas; superação da sinonímia entre negro/a e escravo/a (e suas derivações: libertos/as, ingênuos/as, livres, africanos/as) e, finalmente, tentativa de superação do mito da democracia racial, que determinou relações sociais e influenciou parte das pesquisas realizadas durante o século XX.

Nesse processo de transformação da historiografia da educação, a existência de pessoas negras proeminentes, majoritariamente homens, atuando desde o período em que ainda vigia a escravidão, deixou de ser vista como excepcional. Uma vertente da historiografia incorporou esses sujeitos, sob a categoria de intelectuais, literatos ou letrados negros. A notoriedade que obtiveram especialmente na transição do Império para a República e nas primeiras décadas do regime republicano no Brasil vem ganhando espaço nas preocupações de pesquisadores da área que, atualmente, incorporam também mulheres negras nesse grupo de intelectuais negros/as. Em diferentes regiões do país, tais figuras atuaram como docentes em diversos níveis educacionais e participaram de variados âmbitos da sociedade como política, literatura, artes, jornalismo, direito e medicina. Pesquisados/as por historiadores/as da educação e da história social, alguns exemplos são: maranhenses como Nascimento Moraes (CRUZ, 2016), Maria Firmina dos Reis (CRUZ, 2018) e/ou radicados no Rio de Janeiro como Philippe José Alberto Júnior (VILLELA, 2012) e Hemetério José dos Santos (SILVA, 2015); baianos como Carneiro Ribeiro (PITANGA, 2019); Cincinato Franca (CAVALCANTE, 2020) e Elias Nazareth (SANTOS, 2020); com atuação no Rio de Janeiro e em São Paulo como Ferreira de Menezes, Luiz Gama, Machado de Assis, José do Patrocínio, Ignácio de Araújo Lima, Arthur Carlos e Teophilo Dias de Castro (PINTO, 2014), André Rebouças (PINTO, SCHUELER, 2012); Manuel Querino e José do Patrocínio (SCHUELER, 2013, 2014); na Corte/capital do país como Israel Soares (SILVA, 2017) e Coema Hemetério dos Santos (SILVA, 2019); em Minas Gerais como Padre Vitor (FONSECA, 2020); no Mato Grosso como Bernardina Rich (GOMES, 2009); no Rio Grande do Sul como Sophia Ferreira Chaves (PERUSSATO, 2019), entre outros e outras. Como nas regiões citadas, um conjunto de homens paraibanos também podem ser compreendidos e analisados como intelectuais negros. 


\section{Dois homens com cor na Parahyba do Norte}

A indicação de "cor" em fontes oficiais ou não-oficiais, ao longo do período imperial e ainda nas primeiras décadas do século XX apontam, para quem as consulta posteriormente, que muito provavelmente o homem ou a mulher em questão não era branco/a. Por outro lado, a ausência da cor (e posteriormente, raça) nem sempre significa brancura do sujeito mencionado, o que representa um desafio para quem estuda as relações raciais no período. O apagamento da cor/raça de acordo com as condições de classe e projeção social, assim como a imprecisão na classificação dos sujeitos e o embranquecimento, processos discutidos em diferentes campos do conhecimento, ganham novos contornos quando o sujeito passa pela escola. Marcus Vinícius Fonseca mostra isso ao discutir as escolas mineiras na primeira metade do século XIX:

Encontramos ainda, casos em que alunos figuram como crioulos nas listas nominativas e pardos na documentação das escolas. Isto pode ser tomado como um indicativo de que a escola era um dos espaços utilizados como elemento que conferia status no jogo de definição e qualificação da população negra (FONSECA, 2009, p. 216).

Apesar dessas dificuldades, inerentes ao tema e à documentação disponível, por vezes "rastros e sinais" (GINZBURG, 2007) possibilitam o acesso a homens que não são brancos se movimentando em espaços de prestígio na sociedade paraibana da segunda metade do século XIX às primeiras décadas do século XX. Uma das fontes que permite acessar sua existência é o livro Homens do Brasil em todos os ramos da atividade e do saber - Paraíba, de Manuel Liberato Bittencourt (1914).

Entre dezenas de homens e mulheres ilustres, o autor cita um conjunto de marcadores ao lado de alguns poucos nomes que dão pistas para a compreensão de como esses sujeitos eram percebidos pela sociedade local. Jornalistas, advogados, professores, poetas, autores de livros, funcionários públicos (muitas vezes combinando diferentes papéis), Bittencourt os adjetivou de diferentes maneiras - "mestiço no sangue", "mulato turbulento", "homem de côr". Vale reforçar que as demais centenas de personagens ilustres não têm indicação de qualificações que remetessem a cor/raça seguidas a seus nomes. Alguns deles já foram pesquisados, como o anteriormente citado Graciliano Fontino Lordão (BARROS, 2018), Manuel Cardoso Vieira (ROCHA, 2012), Elyseu Elias Cesar (DOMINGUES, ROCHA, FLORES, 2019) e Vicente Gomes Jardim (BARROS, 2020). Outros permanecem no anonimato, e até agora sabemos de sua existência apenas por serem verbetes na obra indicada, carecendo de estudos mais aprofundados. 
Nesse sentido, apresentaremos dois sujeitos: Cícero Brasiliense de Moura e Ricardo Phillipe da Rocha, cujas trajetórias ainda não foram exploradas pela historiografia.

\title{
Cícero Brasiliense de Moura (1863-1927)
}

O documento "Relação dos Fundadores do IHGP - Breves Notas", contendo pequenos verbetes, traz em ordem alfabética, como o $9^{\circ}$ nome entre os fundadores do Instituto Histórico Geográfico Paraibano, o de CÍCERO BRASILIENSE DE MOURA, identificado como "PROFESSOR E JORNALISTA":

\begin{abstract}
Nasceu na capital da então Província da Paraíba, em 1857. Exerceu os cargos de Chefe de Polícia e Procurador Fiscal dos Feitos da Fazenda Estadual. Dedicou-se ao magistério como Professor do Liceu Paraibano e Escola Normal Oficial do Estado. Além de advogado militante, tornou-se vigoroso jornalista, destacando-se como dos principais redatores de $A$ Gazeta da Paraíba e de $A$ Imprensa. Faleceu aos 28 de julho de 1927 (IHGP, $\mathrm{s} / \mathrm{d})$.
\end{abstract}

Sua cor não é mencionada, e só sabemos que se trata de um sujeito que não era considerado branco porque em 1914 o livro sobre os "paraibanos ilustres" o descrevia:

Professor, advogado e jornalista. Nasceu na Parahyba mais ou menos em 1863. Mestiço no sangue, demasiado modesto, desconhecido quasi, é, no entanto, superior na intelligencia e profundo na illustração. Vive no seu recanto, de onde só sae forçado pelas circumstancias: para dar aula no lyceu ou na escola normal, ou para advogar alguma causa justa. Com decidida queda para as conquistas intellectuais, é jornalista de pulso, advogado influente e homem de largo conceito á Parahyba (BITTENCOURT, 1914, p. 111, grifos nossos).

Diferente de outros nomes como Lordão e Cardoso Vieira, não encontramos informações sobre a origem do autor ou referência sobre sua escolarização. Nascido "mestiço no sangue" em 1857, no auge da escravidão, quem teriam sido seus pais? Que artifícios foram empregados para alcançar a escola, frequentar o curso de Direito e ser professor das instituições de maior prestígio na região, o Liceu Paraibano e a Escola Normal da Paraíba?

Ele foi redator dos jornais $A$ Gaz̧eta da Paraíba e A Imprensa. Concomitante à atuação como jornalista, foi Juiz de Direito e Presidente do Conselho de Intendência da Capital. Foi presidente da Comissão Seccional de Alistamento Eleitoral e atuou como delegado e como advogado na Cidade da Parahyba, na década de 1890. Há registros de Moura como procurador fiscal entre 1901 e 1905. Além disso, lecionou no Liceu Paraibano desde 1890, sendo esta a última função que exerceu na província antes de falecer em 1927.

É importante notar que Cícero Brasiliense de Moura, chamado de "mestiço" pelos 
contemporâneos, foi professor durante muitos anos no Liceu. Embora as fontes encontradas ainda não permitam responder a essa questão, vale refletir sobre possíveis impactos em ter um professor negro e o que poderia causar aos alunos dessa instituição de prestígio na sociedade paraibana. Cardoso Vieira também havia estudado e lecionado no Liceu anos antes, e Graciliano Fontino Lordão o frequentou nos anos 1870. Ou seja, é preciso ressaltar a presença negra nessa instituição da elite paraibana. Da mesma maneira, Cícero Brasiliense de Moura atuou na Escola Normal, ministrando aulas de francês, português e de história geral (Almanak do Estado da Paraíba, 1899, p. 107) contribuindo para a formação de professores na região.

As fontes são escassas e pouco dizem sobre o impacto da presença desse "mestiço de sangue" nos ambientes que percorria. Mas, outros sujeitos tinham sua cor inequivocamente mencionada, como o "pretinho” Ricardo Rocha, consagrado padre no início da República.

\section{Ricardo Philippe da Rocha}

Na obra O Tambiá da minha infância (1941), o memorialista Coriolano de Medeiros rememora seus primeiros anos no bairro homônimo da capital paraibana, nas duas décadas finais do século XIX. Entre os vizinhos, alguns dos personagens eram homens e mulheres de cor e um deles era Padre Ricardo, que teria causado furor por ter conseguido a ordenação a despeito de sua origem:

\footnotetext{
No outro lado erguia-se a ampla vivenda do funileiro Ricardo da Rocha, homem de cor, muito estimado por sua educação, por sua atividade. Ordenou um filho, o Padre Ricardo, muito pretinho e risonho. Foi homem digno, honrou o nome de sua terra, morreu membro acatado e ilustre do clero paraense. No dia em que o Padre Ricardo chegou à casa paterna, após sua ordenação, todo o bairro moveu-se para ver o êxito do esforço do velho e honrado funileiro. Mas o que positivamente surpreendia era a singularidade de ter o seminário de Olinda permitido que um preto conseguisse ser também vigário de Cristo! (MEDEIROS, 1994, p. 32, grifos nossos).
}

Apesar da comoção causada pelo "pretinho Ricardo", a existência de padres negros não era algo totalmente incomum no Brasil Colônia e Império e como mostram investigações sobre os séculos XVIII e XIX sobre o Padre José Maurício Nunes Garcia (1767-1830), que atuou na Corte (SOUZA, LIMA, 2007); o amazonense Padre Daniel Pedro Marques de Oliveira (1828-1881) (ABREU, 2015); e o já mencionado Padre Victor (1827-1903), do sul mineiro (FONSECA, 2020).

A referência feita por Coriolano Medeiros indicou a existência desse personagem, mas outras fontes permitem uma maior compreensão de sua trajetória, apesar das lacunas existentes. Segundo a documentação produzida entre 1890 e 1891, para o processo de ordenação na Igreja Católica, Ricardo Philippe da Rocha nasceu em 1867, filho legítimo de Ricardo Antônio Luis da Rocha e de Genuina Maria da Conceição Rocha, casados em 1866 e moradores da Freguesia de 
Nossa Senhora das Neves, na capital da província. Seus avós também foram identificados: Antonio Luis da Rocha e Rosa Margarida de S. José, pelo lado paterno, e Braz Mariano das Dores e Barbara Maria da Conceição pelo materno. Nenhum deles teve condição jurídica ou cor registradas, mas o candidato a padre foi descrito como "pardo". A atividade do pai seria a de "funileiro", enquanto as testemunhas o apresentavam como artista e a mãe associada a "serviços domésticos". Diferente da informação dada pelo memorialista, Ricardo Phillipe da Rocha não frequentou o Seminário de Olinda, mas foi aluno da Diocese do Pará. No período em que se desenvolvia o processo, o noviço se encontrava frequentando o Seminário de S. Sulpício, em Paris, França e sua documentação foi assinada tanto pelo pai quanto pela mãe do estudante.

Ricardo, nascido de pais livres, decerto havia frequentado aulas de primeiras letras na Parahyba do Norte e o seminário episcopal entre a década de 70 e a de 80, já que em 1891 estava pronto para ser ordenado padre. Ele teria aprendido as primeiras letras no mesmo período em que "meninos pobres" buscavam a escola, conforme citavam relatórios provinciais no início da década (BARROS, 2017). Que aulas teria frequentado? O pai funileiro seria um dos artistas e operários mencionados pelo presidente da província como parte da população que buscava escola para os filhos, ocupando as aulas diurnas da capital? Ou entre os "esforços" de seu pai, como Coriolano de Medeiros rememora, estaria o de arcar com um professor particular? Apesar das imprecisões, ele foi consagrado padre no limiar do XX. Em 1896, o jornal A União publicava uma breve nota: "PADRE RICARDO ROCHA. Vindo do Pará, acha-se entre nós o illustrado sacerdote Ricardo Rocha, uma das verdadeiras glorias de nossa terra natal, que tanto o admira. Nós o cumprimentamos affectuosamente" ( $A$ União, 01/07/1896). Não encontramos indícios de como se deu sua ligação com o Pará, mas sabemos que além de ter estudado naquela província, o Padre Ricardo ali fez sua carreira religiosa, pois anos depois era mencionado: "Vindo do Pará, onde exerce dignamente o cargo de Secretario do Bispado" (A União, 06/11/1898). Em 1920, data de sua última aparição nos jornais disponíveis na Hemeroteca Digital da Biblioteca Nacional, Padre Ricardo continuava ligado à Arquidiocese paraense, compondo uma comissão da cerimônia religiosa das festas pelo jubileu da Guerra do Paraguai (Estado do Pará, 29/02/1920).

O pai de Padre Ricardo era funileiro, compondo o grupo de operários e artistas nas comemorações cívicas e religiosas. Em 1897, com o filho já ordenado padre, ele aparece compondo a $2^{\circ}$ noite dos artistas, numa festividade, ao lado de outros artistas: 
Srs. Vicente Gomes Jardim, Augustinho Cavalcante De Lacerda Lima, Francisco da Silva Lisboa, Ricardo Antônio Luiz da Rocha, Augusto José Queiroz, Antônio Pereira Jurubeba, Luiz França Machado, Manoel Lopes de Mello, Tobias de Pace e Luiz Amendoim (Almanak do Estado da Parahyba, 1897, grifos nossos).

Nesta lista, vale atentar para a presença de Vicente Gomes Jardim, outro paraibano pardo que se destacou como pedreiro, arquiteto e autor de livros técnicos nesse período (BARROS, 2020). Há outros registros que aproximam esses homens. Por exemplo, a convocação para júri em que Cícero Brasiliense de Moura aparece nas mesmas listas que Vicente Gomes Jardim, ou o fato de Cícero Brasiliense de Moura ter como endereço a Rua Sete de Setembro, mesma rua que alguns anos antes Padre Ricardo da Rocha aparecia pagando imposto predial (A União, 1896). Tais elementos são pistas para pensarmos em possíveis redes de sociabilidade entre tais sujeitos.

\title{
À guisa de conclusão
}

Nesse texto, privilegiamos mostrar a existência de homens negros letrados que se destacaram na sociedade paraibana num período em que, até pouco tempo, a historiografia e o senso comum consideravam ser algo impossível para pessoas negras. Suas trajetórias demonstram as diferentes possibilidades de ser negro no Império e nos primeiros anos republicanos, reforçando que existem muitas maneiras de investigar a relação entre populações negras, instrução e a cultura escrita no período. Apesar dos obstáculos que a população negra enfrentava no que se relacionava à instrução, é viável pensar a história da educação da população negra no Brasil não apenas pelo viés da exclusão ou da precariedade.

Tratar da existência desses sujeitos não significa deixar de lado o racismo que permeava a sociedade e, certamente, definia suas experiências. Os primeiros anos republicanos produziram o apagamento dessas figuras:

\begin{abstract}
Do ponto de vista da maioria dos intelectuais reformistas, era preciso democratizar a terra, a educação e o sufrágio popular, não necessariamente nessa ordem. Talvez em função disso, os planos de reforma e a mobilização dos libertos se mantiveram sem comunicação - apartados pelo éthos colonial predominante entre os brasileiros letrados, independentemente da cor, e pelo estranhamento decorrente, o qual se tornaria cada vez mais suscetível de leituras raciais no limiar do século XX. As trajetórias melancólicas de José do Patrocínio e André Rebouças na primeira década republicana são paradigmáticas das frustrações produzidas por esse desencontro (MATTOS, 2009, p. 30).
\end{abstract}

Consideramos que tal processo e a posterior invisibilidade que tais sujeitos continuam tendo na historiografia e na produção de materiais escolares, no apagamento desses homens e mulheres que nomeiam logradouros, escolas, maternidades, reforça a importância de se destacar as 
trajetórias de negros letrados, professores, funcionários públicos, políticos, trabalhadores especializados, escritores, padres, que tiveram destaque local e visibilidade no cenário provincial/estadual. Sua presença em espaços escolares e o domínio de símbolos ligados ao letramento desde o final do período imperial fortalecem os elementos para a denúncia da situação posterior. Anônimos como meninos e meninas pretos e pardos nas escolas primárias e em instituições para a infância pobre, adultos frequentando a escola noturna ou escravizados que sabiam ler e escrever informam que as populações negras não assistiam passivamente a mudança da sociedade brasileira no que se referia ao universo letrado.

Outros, que se destacaram como Cícero Brasiliense de Moura e Ricardo Philippe da Rocha, representam outras possibilidades de ser negro no Brasil. Suas trajetórias ilustram as tensões vividas por uma minoria negra que, apesar das interdições advindas da pertença racial, conseguiu se destacar, demonstrando a complexidade das relações raciais no Brasil Imperial. Não sem custos, à despeito da origem, eles conseguiram se impor, colaborando para o desenvolvimento da sociedade paraibana, disputando respeito e reconhecimento. Apesar da escassez de fontes, é instigante pensar em suas contribuições para a formação de outros sujeitos, parte dos/as inúmeros/as negros/as anônimos/as que se relacionavam com o ambiente letrado que estava sendo forjado na Parahyba do Norte e em outras regiões por onde estiveram.

\section{Referências}

Almanack do Estado da Paraíba, Escola Normal, Parahyba do Norte: Imprensa Oficial, ed. 1, 1899. Disponível em:

http:/ / memoria.bn.br/DocReader/docreader.aspx?bib $=820261$ \&pasta $=$ ano $\% 20189$ \&pesq $=\mathrm{c} \%$ C3\%ADcero\%20brasiliense \%20de\%20moura\&pagfis=125 Acessado em 03 abr 2021.

A União. Padre Ricardo Rocha. 01 jul 1896. Disponível em: http://memoria.bn.br/DocReader/DocReader.aspx?bib=171239\&pesq=Ricardo \%20Rocha\&pa sta $=$ ano $\% 20189 \&$ pagfis $=1225$ Acessado em 03 abr 2021.

A União. Padre Ricardo Rocha. 06 nov 1898. Disponível em: http://memoria.bn.br/DocReader/DocReader.aspx?bib=171239\&Pesq= $\% 22 \% 20 \mathrm{Padre} \% 20$ Ric ardo $\% 22$ \&pagfis $=3178$ Acessado em 03 abr 2021.

BARROS, Surya Aaronovich Pombo de. FONSECA, Marcus Vinicius. A história da educaşão dos negros no Brasil. Niterói: PENESB: EDUFF, 2016.

BARROS, Surya Aaronovich Pombo de. Escravos, libertos, filhos de africanos livres, não livres, pretos, ingênuos: negros nas legislações educacionais do XIX. Educação e Pesquisa, São Paulo, v. 42, n. 3, p. 591-605, Set. 2016. Disponível em: <http://www.scielo.br/scielo.php?script=sci_arttext\&pid=S1517-

97022016000300591\&lng=en\&nrm=iso> . Acesso em 08 abr. 2021. 


\section{Dialogia}

BARROS, Surya Aaronovich Pombo de. Intelectuais negros entre o século XIX e início do XX: novas perspectivas para a história da educação brasileira

BARROS, Surya Aaronovich Pombo de. Graciliano Fontino Lordão: um professor 'de côr' na Parahyba do Norte. Revista Brasileira De História Da Educaşão, 18, e033. Disponível em: https://periodicos.uem.br/ojs/index.php/rbhe/article/view/44836 Acesso em 01 abr 2021.

BARROS, S. A. P. de. Vicente Gomes Jardim: um "artista" e autor "de cor" no final do século XIX e início do XX. Resgate: Revista Interdisciplinar de Cultura, Campinas, SP, v. 28, p. e020024, 2020. Disponível em:

https://periodicos.sbu.unicamp.br/ojs/index.php/resgate/article/view/8658603 Acesso em: 8 abr. 2021.

BITTENCOURT, Liberato. Homens do Brasil. Em todos os ramos da atividade e do saber, de 1500 aos nossos dias. Volume II. Parahyba (Parahybanos Illustres). Rio de Janeiro: Livraria e Papelaria Gomes Pereira Editor, 1914.

CAVALCANTE, Ian. Educando libertos, escravizados e operários: A trajetória do professor Cincinato Franca, Bahia 1860-1934. Tese (Doutorado em Educação), Niterói: UFF, 2020.

CRUZ, Marileia dos Santos. A produção da invisibilidade intelectual do professor negro Nascimento Moraes na história literária maranhense, no início do século XX. Revista Brasileira de História, vol.36, n.73, 209-230, 2016.

CRUZ, Mariléia dos Santos; MATOS, Érica de Lima de; SILVA, Ediane Holanda. "Exma. Sra. d. Maria Firmina dos Reis, distinta literária maranhense": a notoriedade de uma professora afrodescendente no século XIX. CEMOrOc-Feusp/Univ. Autònoma de Barcelona, set/dez 2018 (p. 151-166).

DOMINGUES, Petrônio, ROCHA, Solange Pereira da, FLORES, Elio Chaves. As artes e os ofícios de um letrado afro-diaspórico: Eliseu César (1871-1923). Revista Afro-Ásia, n. 60, 2019 p. 105-147.

Estado do Pará. Guerra do Paraguay. Disponível em:

http://memoria.bn.br/DocReader/DocReader.aspx?bib=800082\&pesq=padre $\% 20$ Ricardo $\% 20$

Rocha\&pasta $=$ ano\%20192\&pagfis $=19398$ Acessado em 02 abr 2021.

FONSECA, Marcus Vinícius. A arte de construir o invisível: o negro na historiografia educacional brasileira. Revista Brasileira de História da Educação, Campinas, v. 13, p. 11-50, 2007.

FONSECA, Marcus Vinícius. Apontamentos para uma problematização das formas de classificação racial dos negros no século XIX. Revista Educação Pública, Cuiabá, v. 18, n. 36, p. 201 219, jan./abr. 2009 p. 201-219

FONSECA, Marcus Vinícius. Padre Vitor: um educador negro entre a escravidão e a santidade. Revista Brasileira de História da Educação, Maringá , v. 20, e131, 2020 • p. 1-26

GINZBURG, Carlo. O fio e os rastros: verdadeiro, falso, fictício. São Paulo: Companhia das Letras, 2007.

GOMES, Nailza Costa. Uma professora negra em Cuiabá na Primeira República: limites e possibilidades. Dissertação (Mestrado em Educação). Cuiabá: UFMT, 2009. 


\section{Dialogia}

BARROS, Surya Aaronovich Pombo de. Intelectuais negros entre o século XIX e início do XX: novas perspectivas para a história da educação brasileira

INSTITUTO HISTÓRICO E GEOGRÁFICO PARAIBANO/IHGP. Sócios Fundadores do IHGP (BREVES NOTAS), s/d. Disponível em:

http://www.ihgp.net/socios_fundadores.htm Acessado em 02 de abril de 2021.

MATTOS, Hebe. Raça e Cidadania no crepúsculo da modernidade escravista no Brasil. In K. Grinberg, R. Salles (orgs.). O Brasil Imperial, volume 3: 1870-1889. Rio de Janeiro, RJ: Civilização Brasileira, 2009.

MEDEIROS, Coriolano de. O Tambiá da minha infância, João Pessoa: A União, 1994 [1942].

O Publicador, Annuncios, 7 jul 1865. Disponível em

http:/ / memoria.bn.br/DocReader/DocReader.aspx?bib $=215481$ \&pesq $=\% 22$ sabe $\% 201$ er $\% 22 \&$ pagfis=1034 Acessado em 07 abr 2021

O Publicador, Correpondencia, 22 jul 1868. Disponível em

http://memoria.bn.br/DocReader/docreader.aspx?bib=215481\&pasta=ano $\% 20186 \& p e s q=G r a$ ciliano\&pagfis $=4340$ Acessado em 07 abr 2021

PINTO, Ana Flávia M. Fortes laços em linhas rotas: literatos negros, racismo e cidadania na segunda metade do século XIX. Tese (Doutorado em História). Universidade Estadual de Campinas, Campinas, 2012.

PITANGA, Ismael. Ernesto Carneiro Ribeiro: A trajetória intelectual do Professor Negro Baiano (séculos XIX-XX). 30 Simpósio Nacional de História. Anais... ANPUH, 2019.

ROCHA, Solange Pereira da. Cardoso Vieira, um homem negro na composição das elites da Paraíba Oitocentista; Biografia, Memória e História. Revista Crítica Histórica, n. 6, ano III, 2012, p. $1-18$

SANTOS, Sivaldo dos Reis. "O Nobre Educador" da Bahia: trabalho, cidadania e sociabilidades. Trilhas da História, v. 10, n. 19, ago-dez, ano 2020 p. 92-110

SCHUELER, Alessandra Martinez F.; PINTO, Rebeca Natacha de. Intelectuais negros e reformas sociais: pensamentos e projetos educacionais do Professor André Pinto Rebouças. In Anais do IX Seminário nacional de estudos e pesquisas "História, Sociedade e Educação no Brasil". João Pessoa, PB, 2012.

SCHUELER, Alessandra Martinez F. de. "Fazer artes e viver de ofícios": trabalho, liberdade e educação no pensamento de Manuel Raymundo Querino (1851-1923). Anais do XXVII Simpósio Nacional de História da ANPUH. Natal, RN, 2013.

SCHUELER, Alessandra Martinez F. de. Educação e abolição como projetos de reforma social: trajetória intelectual e propostas educacionais de José do Patrocínio. VENÂNCIO, Giselle; VIANNA, Larissa M.; SECRETO, María Verónica (org.). Sujeitos da História: perspectivas e abordagens. Niterói: EDUFF, 2015.

SILVA, Luara Santos. 'ETYMOLOGIAS PRETO': Hemetério José dos Santos e as questões raciais de seu tempo (1888-1920). Dissertação (Mestrado em Relações Etnicorraciais). Rio de Janeiro: CEFET/RJ, 2015. 


\section{Dialogia}

BARROS, Surya Aaronovich Pombo de. Intelectuais negros entre o século XIX e início do XX: novas perspectivas para a história da educação brasileira

VILLELA, Heloísa O. S. A trajetória de um professor negro no Brasil escravocrata. OLIVEIRA, Iolanda (org.). Relações Raciais no Contexto Social, na Educação e na Saúde. Brasil, Cuba, Colômbia e África do Sul. Rio de Janeiro, Quartet, 2012. 